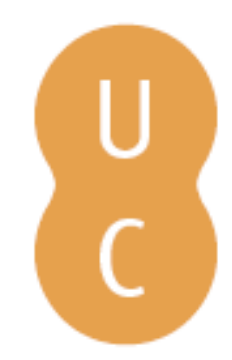

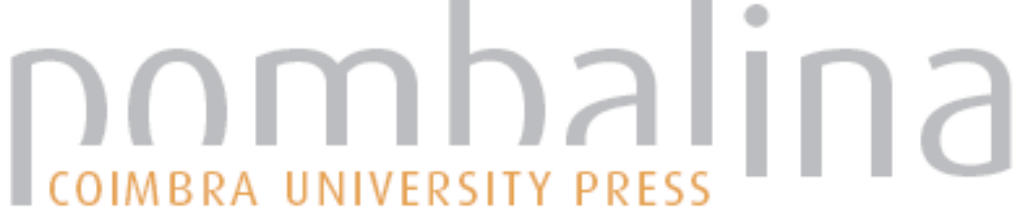

\section{Uma evolução não-Darwinista, no Brasil}

Autor(es): Domingues, Heloisa Maria Bertol

Publicado por: Imprensa da Universidade de Coimbra

URL

persistente:

URI:http://hdl.handle.net/10316.2/32363

DOI:

DOI:http://dx.doi.org/10.14195/978-989-26-0325-4_2

Accessed : $\quad$ 26-Apr-2023 11:12:54

A navegação consulta e descarregamento dos títulos inseridos nas Bibliotecas Digitais UC Digitalis, UC Pombalina e UC Impactum, pressupõem a aceitação plena e sem reservas dos Termos e Condições de Uso destas Bibliotecas Digitais, disponíveis em https://digitalis.uc.pt/pt-pt/termos.

Conforme exposto nos referidos Termos e Condições de Uso, o descarregamento de títulos de acesso restrito requer uma licença válida de autorização devendo o utilizador aceder ao(s) documento(s) a partir de um endereço de IP da instituição detentora da supramencionada licença.

Ao utilizador é apenas permitido o descarregamento para uso pessoal, pelo que o emprego do(s) título(s) descarregado(s) para outro fim, designadamente comercial, carece de autorização do respetivo autor ou editor da obra.

Na medida em que todas as obras da UC Digitalis se encontram protegidas pelo Código do Direito de Autor e Direitos Conexos e demais legislação aplicável, toda a cópia, parcial ou total, deste documento, nos casos em que é legalmente admitida, deverá conter ou fazer-se acompanhar por este aviso.

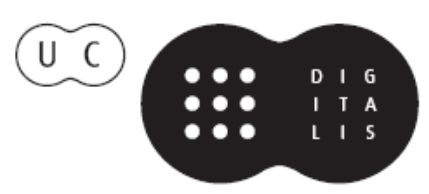


Ana Lennar Pereira

Helaísa B. Damingues

Jũan Rui Pita

Dswaldo Salaverry
A Natureza as suas Histórias e os seus Caminhos

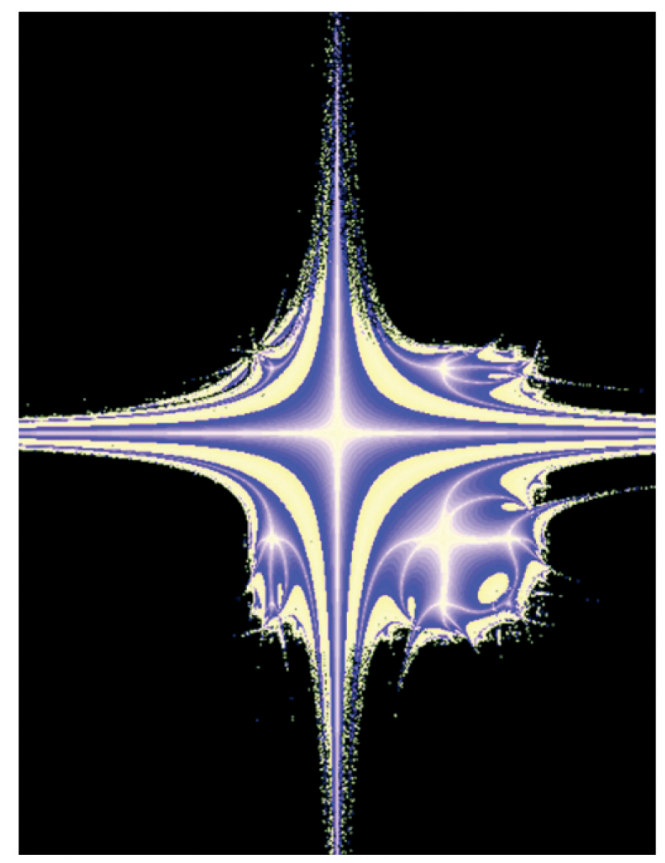


(Página deixada propositadamente em branco) 


\section{ANA LEDNDR PEREIRA \\ HELIISA BERTLL DIMINELESS \\ JIÃ̄ RU PITA \\ GSWALDO SALAVERRY GARCIA}

\section{A NATUREEZA, \\ AS SUAS HISTÓR|AS \\ E IS SELS CAMINHIS}

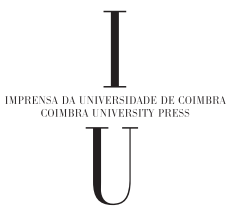

- colmbra 2006 
(Página deixada propositadamente em branco) 
(Página deixada propositadamente em branco) 


\section{Coordenação Científica da Colecção Ciências e Culturas}

João Rui Pita e Ana Leonor Pereira

Os originais enviados são sujeitos a apreciação científica por referees

\section{Coordenação Editorial}

Maria João Padez Ferreira de Castro

\section{Edição}

Imprensa da Universidade de Coimbra

Email: impresauc@ci.uc.pt

URL: http://www.imp.uc.pt • Normas de publicação de colecções

Design

António Barros

Pré-Impressão

António Resende

Imprensa da Universidade de Coimbra

Capa

Ernesto Melo e Castro

Sem título, 2003

Fractais originais gerados no Fractint

Tratados no Photoshop 7.0

Col. António Barros, Coimbra

Impressão e Acabamento

SerSilito $•$ Maia

\section{ISBN}

978-989-8074-13-3

\section{Depósito Legal}

$263187 / 07$

Obra publicada com a colaboração de:

2

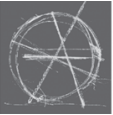

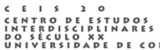

Obra publicada com o apoio de:

FCT Fundação para a Ciência e a Tecnologia

MINISTÉRIO DA CIÊNCIA, TECNOLOGIA E ENSINO SUPERIOR Portugal

Programa Operacional Ciência, Tecnologia, Inovação do Quadro Comunitário de Apoio III

(C) 2006, Imprensa da Universidade de Coimbra 
Heloisa Maria Bertol Domingues

Museu de Astronomia e Ciências Afins/Ministério da Ciência e da Tecnologia - MAST-MCT

- Rio de Janeiro

\section{UMA EVOLUÇÃO NÃO-DARWINISTA, NO BRASIL}

É comum a associação entre darwinismo e evolucionismo, a tal ponto que chegase a confundir a teoria de Darwin com a idéia de evolução, e grandes opositores da teoria darwiniana têm sido chamados de darwinistas. A teoria de Darwin teve repercussões ideológicas amplas, pois colocava em jogo a idéia de criação, o que foi chocante na maioria dos países de tradição católica, como eram praticamente os países ibero-americanos, embora no Brasil sua recepção pareça ter sido menos problemática ${ }^{1}$. A difusão não dependia do mero consenso dos especialistas, e já no final do século XIX se deslocou para o social, em que obteve aceitação, principalmente via Spencer. Entretanto, as vozes contrárias também se manifestaram. Mesmo nos meios da Biologia o evolucionismo que se admitia, embora, muitas vezes, pudesse ter sido confundido com darwinismo, em geral não o era ${ }^{2}$.

$\mathrm{Na}$ introdução do livro The comparative reception of Darwinism Thomas Glick comentou que o próprio Darwin observara que a recepção às suas idéias havia sido diferente segundo as nacionalidades ${ }^{3}$. No Brasil, a teoria da evolução confundiu-se com darwinismo, porém, nem sempre o que se dizia ser derivado de Darwin o era necessariamente e aconteceu que alguns opositores a ele permaneceram na memória coletiva como darwinistas. Resistências e partidarismos à teoria revolucionária conviveram, no país, no final do século XIX.

Frequentemente, a difusão da teoria de Darwin se deu através da obra de outros cientistas. Na América espanhola e portuguesa, conforme observaram Rosaura Ruiz e Francisco Ayala, é importante considerar Ernst Haeckel, Herbert Spencer e Francis Galton. O primeiro foi o mais importante dos difusores do darwinismo no século XIX e os outros dois tiveram um papel fundamental na extensão das idéias de Darwin para âmbitos que este jamais pensou quando elaborou sua teoria, tais como o da evolução

\footnotetext{
${ }^{1}$ Glick, Thomas, Introdução. Domingues, Heloisa M. B., Romero SÁ, Magali e Glick, T. (Org.), A recepção do Darwinismo no Brasil, Rio, Editora FiocruZ, 2003; PrUnA, P. M. E GonZales, Armando G., Darwinismo y Sociedad em Cuba - Siglo XIX - Madrid, CSIC, 1989, Introdução; GLICK, T. and KoHN, David, Charles Darwin - On evolution, Indianápolis, Hackett Publishing Company, 1984.

2 PRUNA et alli, idem.

${ }^{3}$ GLICK, Thomas (Ed.), The comparative reception of Darwinism. Chicago, The University of Chicago Press, 1988; First ed. 1976.
} 
social humana e o do melhoramento da espécie humana ${ }^{4}$. No Brasil, além do próprio Darwin, os dois primeiros tiveram papel relevante, porém, a Galton não se encontram referências no século XIX, como se encontram em outros países. Por exemplo, na Argentina, as teorias de Galton jogaram forte papel e a eugenia se organizou no país desde a década de 70 do século XIX ${ }^{5}$. Na antropologia brasileira, no seu início, as teorias dos opositores a Darwin, como a de Quatrefages de Bréau (tido como o 'pai' da teoria da superioridade do homem branco) e a de seu antecessor Paul Broca, foram de muito maior importância, como se verá.

$\mathrm{Na}$ Europa, a recepção da teoria não foi diferente. Ali também se defrontaram as resistências e os partidarismos, como no caso da Alemanha. Para William Montgomery, na Alemanha, a teoria de Darwin teve implicaçôes sociais, principalmente no tocante à religião, tendo aderido a ela os intelectuais mais jovens, livre-pensadores e materialistas. Entre estes, o autor enumerou Fritz Müller que vivia no Brasil ${ }^{6}$. Na França, até 1880, os biólogos desconheciam a palavra darwinismo. Eram apenas transformistas, sublinhou Robert Stebins ${ }^{7}$. No país de Lamarck, Darwin foi somente mais um fator do evolucionismo ${ }^{8}$. Em Portugal, conforme sublinhou Ana Leonor Pereira, não foi negligenciável a difusão do darwinismo, nos meios intelectuais, para além da biologia, como na filosofia, na história ou na engenharia social, porém, a tradição impôs uma interpretação da teoria que, conforme observado, mais se aproximou do anti-darwinismo9. Levando em conta a visão mais radical de Patrick Tort, as teorias que foram consideradas derivadas de Darwin, mesmo as idéias de Haeckel, não podem ser vistas como darwinistas ${ }^{10}$.

\section{O surgimento do darwinismo no Brasil}

O Brasil foi palco privilegiado da construção da teoria da seleção natural das espécies, mas serviu também à afirmação de seus opositores. Entre os primeiros darwinistas, como Fritz Müller ${ }^{11}$, e os grandes opositores, como Louis Agassiz ${ }^{12}$, surgiram trabalhos

\footnotetext{
${ }^{4}$ Ruiz, Rosaura y Ayala, Francisco J., El núcleo duro del darwinismo, GLICK, T. RUiz, R. y Puig-Samper, M.A., (Editores), El darwinismo em Espana e Iberoamérica, Madrid, Dolce Calles, México, UNAM, 1999, p. 299-322.

${ }_{5}^{5}$ Miranda, Marisa y Vallejo, Gustavo (Editores), Darwinismo social y eugenesia en el mundo latino. Buenos Aires, Ed. Siglo XXI de Argentina, 2005.

${ }^{6}$ Montgomery, William M., Germany, in GLiCK, 1976, op. cit., p. 81-116.

${ }^{7}$ STEbins, Robert E., France, in GLICK, 1976.

${ }^{8}$ Idem.

9 Pereira, Ana Leonor, Darwin em Portugal, Filosofia, História, Engenharia Social (1865-1914), Coimbra, Livraria Almedina, 2001.

${ }^{10}$ TorT, Patrick, (Org.), Darwinisme et Societé. Paris, Presse Universitaires de France, 1992.

11 West, David, Fritz Muller, A Naturalist in Brazil. Blacksburg, Virginia, EUA, Pocahontas Press, 2003.

${ }^{12}$ Galvão, Gastão, As palestras de Louis Agassiz no Colégio Pedro II, na volta da Amazônia. III Colóquio Internacional sobre Darwinismo na Europa e Américas, Manaus, Amazonas, Setembro de 2004.
} 
de alguns brasileiros em que afloraram as divergências em relação à teoria da seleção natural das espécies ${ }^{13}$.

O Brasil era um país alvo de viagens naturalistas, aliás, como é sabido, estas foram o meio pelo qual se desenvolveram as ciências naturais. Foi também em tais viagens que se concretizou a teoria da seleção das espécies bem como afirmaram-se os seus opositores. Da viagem do Beagle e do diálogo entre Bates e Wallace, que durante anos permaneceram na Amazônia colhendo espécies e estudando a singularidade do meio ambiente, surgiu a conhecida teoria darwinista ${ }^{14}$. Wallace chamou a atenção pela primeira vez para a biodiversidade e abriu um debate polêmico com Darwin sobre a prioridade da teoria, o que é bastante conhecido ${ }^{15}$.

Darwin, passou quatro meses no Brasil, em 1832, durante a sua viagem à América do Sul, tendo pela primeira vez entrado em contato com a floresta tropical. Numa passagem do seu diário escreveu: «Brasil, 29 de fevereiro: - O dia passou deliciosamente. Mas «delícia» é termo insuficiente para exprimir as emoções sentidas por um naturalista que, pela primeira vez, se viu a sós com a natureza no seio de uma floresta brasileira." Quando da sua passagem pelo Rio de Janeiro, Darwin visitou o Jardim Botânico onde observou que: "cresciam plantas muito conhecidas pela grande utilidade de suas propriedades» ${ }^{16}$. Não fez, no entanto, nenhuma referência aos naturalistas brasileiros.

O Brasil não foi somente o palco da elaboração da teoria da evolução por seleção natural. Ao contrário, foi nele que nasceu imediatamente um suporte à ela. Foi no Brasil que surgiu, no século XIX, uma das mais importantes interpretações da teoria na área da biologia, através dos trabalhos do naturalista, imigrante alemão, Fritz Müller. Müller, em 1864, ficou conhecido no meio científico internacional pela publicação de um pequeno livro intitulado Für Darwin, no qual demonstrou aquela teoria, através de estudos embriológicos em crustáceos ${ }^{17}$. A repercussão deste livro nos círculos científicos alemães e ingleses foi imediata, sendo que a sua tradução para o inglês foi sugerida pelo próprio Darwin, e apareceu em 1869. Müller tornou-se amigo e colaborador de Darwin, com quem trocou correspondência, abordando seus estudos sobre diferentes grupos de animais e vegetais e enviando-lhe material para estudo ${ }^{18}$. Entre 1876 e 1891, trabalhou como viajante naturalista do Museu Nacional em cuja revista, os Archivos do Museu Nacional, publicou 17, dos seus 248 artigos sobre insetos, crustáceos e fertilização das plantas, todos relacionados à teoria darwinista ${ }^{19}$. Além de muito poucos, observou David West, seus artigos eram publicados no Brasil

${ }^{13}$ Ver Domingues, Heloisa M. Bertol e Romero SÁ, Magali, The introduction of darwinism in Brazil, Org. Glick, T., Puig-Samper, M. A., Ruiz, R. The reception of Darwinism in Iberian World, Dordrecht, Kluwer Academic Press, 2001, p. 65-81.

${ }^{14}$ Ferreira, R. - Bates, Darwin, Wallace e a Teoria da Evolução. São Paulo, EDUSP, 1990.

15 Idem.

${ }^{16}$ DARWIN, C. - Viagem de um naturalista ao redor do mundo. Trad. J. Carvalho. Rio de Janeiro, Sociedade Editora e Gráfica Ltda., p. 51-52.

${ }^{17}$ MÜLler, Fritz, Für Darwin, Leipzig, Verlag von Williem Engelmann, 1864.

${ }^{18}$ MÜller, F., Notes on some of the Climbing Plants near Desterro, in South America, in a letter to C.Darwin. The Journal of the Linnean Society, , Botany, vol. IX (1865) 344-349.

${ }^{19}$ Archivos do Museu Nacional, vols. II, 1877 (5 artigos); Vol. III, 1878 (4 artigos); Vol. IV, 1879 (5 artigos); Vol. VIII, 1892 (3 artigos). 
dez anos depois de terem sido publicados na Europa ${ }^{20}$. Um silêncio tão longo pode ser tomado como evidência das restriçôes que se fazia ao seu trabalho. Cientista de renome internacional, em 1891, Fritz Muller foi demitido do cargo de viajante-naturalista do Museu Nacional, passando a viver de uma ajuda mensal concedida pela prefeitura de Blumenau, em Santa Catarina, onde residia.

Ainda, do ponto de vista das relações sociais das ciências, o darwinismo no Brasil pode ser considerado um país sui generis. Embora o senso comum das ciências tenha popularizado a palavra "darwinismo" para designar diferenças culturais e raciais, quando as estudamos no Brasil percebe-se que não é na teoria de Darwin que se encontram as razões teóricas que justificam estas diferenças, mas, precisamente, nas teorias dos seus opositores. De um lado encontrava-se a discreta, mas forte presença de Fritz Müller (que estava incluído na rede dos teóricos da seleção das espécies), de outro, havia uma prática arraigada das ciências naturais que privilegiava a arqueologia e o método antropológico craniométrico, cujos representantes, também incluídos na rede internacional, enfatizavam sua oposição a Darwin. Por outro, ainda é preciso considerar os trabalhos de naturalistas opositores a Darwin, como o foi Louis Agassiz, que esteve no Brasil na década de 60 do século XIX ${ }^{21}$. Sua viagem ao Brasil teve a finalidade de colher elementos, no mesmo local que servira à construção da teoria da seleção natural das espécies, para destruí-la ${ }^{22}$. É sabido que o naturalista suiço foi ferrenho opositor de Darwin, chegando a criar um museu, nos Estados Unidos, onde se radicou, para provar que os princípios darwinianos estavam errados. Agassiz, no Brasil, teve apoio incondicional do Imperador Pedro II e de diversos naturalistas.

O imperador Pedro II, em carta a Quatrefages de Bréau, um dos muitos cientistas com quem se correspondia e com quem manteve correspondência sistemática, que durou dos anos 1870 até 1891 quando faleceu, dizia: - "Acabo de ler a coleção de cartas do meu amigo Agassiz, publicadas pela viúva. Que teoria ousada! Conversamos muito sobre isto nas duas vezes em que ele esteve no Rio.» (na ida e na volta da viagem à Amazônia) ${ }^{23}$ Pedro II foi um grande incentivador das ciências naturais e um dos únicos governantes, não cientista, eleito membro estrangeiro da Academia de Ciências de Paris, pelas relações que mantinha com os cientistas ${ }^{24}$. Entre os extremos

20 WEST, op. cit.

${ }^{21}$ Agassiz, Louis, Viagem ao Brasil - 1865-1866. São Paulo, Companhia Editora Nacional, 1938.

22 Galvão, G., op. cit.; Roberts, Jon, Louis Agassiz on Polygenism, transmutation and Scientific methodology: a reassessment, III Colóquio Internacional sobre Darwinismo, Manaus, Amazonas, Setembro de 2004.

${ }^{23}$ Carta de Pedro II a Quatrefages: 06 de fevereiro de 1886 (Arquivo da Academia de Ciências de Paris).

${ }^{24}$ Pedro II era filho do primeiro imperador do Brasil, D. Pedro I ou D. Pedro IV, de acordo com a linhagem portuguêsa. Quanto à eleição para a Academia de Ciências de Paris, lê-se nos Comptes Rendus (1875, p. 540541): "Séance du Lundi, 4 mars, 1875; President Frémy; L'Académie procède, par la voie du scrutin à la nomination d'un correspondent pour la section de Géographie et Navigation, en remplacement de feu l'amiral de Wranglell. Au premier tour de scrutin, le nombre de votants étant 57; S. M. don Pedro, empereur du Brésil, obtient 43 souffrages; M. le Géneral Sabine 7soufrages; et M. Cialdi 2 souffrage. Il y a cinq billets blancs. S. M. D. Pedro, ayant réuni la majorité absolue de souffrages, est proclamé correspondent de l'Académie." 
de refutação e aceitação, interveio a figura política do Imperador, que se não a refutava também não a aceitava, mesmo assim a teoria de Darwin tornou-se um referencial para o campo das ciências naturais, no Brasil.

\section{A oposição a Darwin na rede internacional das ciências}

O imperador Pedro II atuou como uma espécie de relações públicas das ciências brasileiras no meio internacional. Relativamente à teoria de Darwin, não se pode dizer que tenha sido um defensor, antes pelo contrário. Nas últimas décadas do século XIX ele facilitou a divulgação da produção científica brasileira e dos seus cientistas no exterior. Na Academia de Ciências de Paris foram publicados centenas de trabalhos e outros discutidos, a maioria enviada por seu intermédio (CITAR). Tanto que ele foi eleito membro estrangeiro da Academia sem ser cientista. Manteve correspondência com diversos cientistas, principalmente da França, mas também da Alemanha. Para estes dois países enviou material arqueológico para análise de Quatrefages e Virchow, respectivamente, dois declarados adversários da teoria da seleção natural das espécies.

Numa de suas cartas a Quatrefages, o Imperador, ao comentar que no Museu Nacional os cientistas trabalhavam diversas questóes sobre a natureza brasileira, afirmava que a doutrina evolutiva, embora se apoiasse em muitos fatos, era decepcionante ${ }^{25}$.. Em outra carta, Pedro II disse a Quatrefages que gostaria de conhecer a opinião dele sobre os macacos antropomorfóides, pois, nada o repugnava mais do que ter que admitir a hipótese desta evolução para a espécie humana. ${ }^{26}$ Ou seja, o Imperador deixava transparecer nesta correspondência que era mais concorde às teses anti-darwinistas de Quatrefages do que simpático ao darwinismo.Com respeito à temática evolucionista a questão da descendência do homem, do macaco, sem dúvida, foi motivo de grande celeuma. A imprensa seguidamente publicava matérias discutindo a hipótese ou divulgando charges irônicas sobre a questão. Pouco antes da sua morte, na França, em 1891, Pedro II reafirmava suas convicções contra o "tal evolucionismo»: "Eu continuo a crer que o primeiro homem não foi nem descendente do macaco, nem tampouco negro. ... vale mais a ignorância cega do que a ilusão da ciência», dizia em outra de suas cartas a Quatrefages ${ }^{27}$.

A Revista Brasileira, publicada no Rio de Janeiro, levou a público um debate sobre a ascendência do macaco ao homem, travado entre Herrmann von Ihering, então diretor do Museu Paulista, e o zoólogo Carlos Euler, em torno do estudo de Dubois sobre o Pithecanthropus. Carlos Euler, um adepto de Haeckel, afirmava que era

(Archives de l'Académie de Sciences de Paris). Por outro lado, $k$ é conhecido o fato de ter Pedro II financiado diversos trabalhos cientificos da Europa, dentre os mais conhecidos encontra-se o financiamento a Pasteur.

${ }^{25}$ Carta de Pedro II a Quatregages; 14 dezembro 1878 (Arquivo da Academia de Ciências de Paris). Paris).

${ }^{26}$ Carta de Pedro II a Quatrefages: 06 de fevereiro de 1886 (Arquivo da Academia de Ciências de

${ }^{27}$ Carta de Pedro II a Quatrefages, escrita de Cannes em 17 de abril de 1891 (Arquivo da Academia de Ciências de Paris). 
impossível negar que as descobertas de Java diminuíram a distância entre o homem e o macaco. Ao contrário, para Ihering, um ex-aluno de Virchow e partidário do método craniométrico, não havia ainda uma conclusão sobre o fóssil do Pithecanthropus, visto que os mais competentes naturalistas não haviam chegado a um consenso e, para ele, aquele fóssil era pequeno demais para ser de um homem, e grande demais para ser de um antropóide 28 .

Tempos antes, a mesma questão, da descendência humana do macaco, tinha sido objeto de debate no Jornal do Comércio do Rio de Janeiro. Em artigo, sem assinatura, intitulado $A$ teoria darwinista, foram apresentadas as experiências de Robinson, na Inglaterra, que ao comparar o instinto do macaco e do bebê, de agarrar-se a mãe, concluíra que ambos eram semelhantes, o que provava a descendência ou pelo menos deixava claro que 'éramos muito semelhantes'. ${ }^{29}$

A teoria da seleção natural das espécies chegava ao Brasil num momento de afirmação da nacionalidade, quando intelectuais e políticos objetivavam colocar o país na «marcha evolutiva da civilização", através da História e da Geografia. Uma das questóes levantadas pelas teorias evolucionistas, na mesma época, foi a da origem da sociedade, o que, no Brasil, foi imediatamente objeto de debates, pois os índios, considerados primitivos e selvagens, eram os primeiros habitantes do país e, ao mesmo tempo, conheciam o interior e as suas riquezas a explorar ${ }^{30}$. Uma solução foi considerá-los 'primitivos', cuja caracterização as ciências naturais se encarregavam de fazer.

Neste contexto, desenvolveu-se a antropologia e a arqueologia no país, com base nos métodos da craniometria, tema que fazia parte das discussões do Imperador com seus interlocutores cientistas. Numa carta de 1873, Quatrefages comentou com o Imperador os resultados dos seus estudos sobre a teoria das raças, dizendo que era uma craniologia geral aplicada à caracterização das raças humanas e que esperava que fosse mais e mais reconhecido que os tipos pré-históricos, os mais antigos, estão ainda representados em populações atuais; que o desenvolvimento das qualidades e faculdades humanas eram independentes da forma do crâneo; o crâneo de Neandhertal, que alguns antropólogos diziam que pertencia a alguma espécie de besta feroz, encontrava-se ainda entre australianos, isto é, «dividindo os mesmos espaços conosco» ${ }^{31}$.

${ }^{28}$ Domingues, H.M.B. e ROMERO SÁ, (2003) 118.

${ }^{29}$ A Teoria Darwinista. Jornal do Comércio, 1893.

${ }^{30}$ Domingues, H. M. Bertol, As ciências naturais e a construção da nação brasileira. Revista de História, 135 (2º semestre 1996) 41-59.

${ }^{31}$ Carta de 2 dezembro de 1873; o livro do qual ele fala, aparentemente, é o Instruçōes para quem de Nicolau Joaquim Moreira publicado neste ano em português e inglês para ser divulgado na Europa e Estados Unidos. Numa outra carta Quatrefages, invocando um trabalho de Grandidier e Edwards que acabava de ser publicado, dizia que este significava um golpe mortal na teoria darwinista com suas pretendidas origens simiescas. Diz que Haeckel pensara encontrar nos Lémuriens a cadeia necessária entre os marsupiais e os macacos, que ele faz nosso ancestral pelo seu intermediário, o homem pithecóide(?), do qual não conhecemos traço algum. Grandidier havia estudado a placenta dos Lémuriens que Haeckel havia acreditado ter uma "caduque'e ser discoidal semelhante nos homens e nos macacos. Porém, Grandidier pudera demonstrar que faltava aos Lémuriens a "caduque» e a sua placenta era difusa como as "angulles», os "edentés» e os Cetáceos(Carta de Quatrefages a Pedro II, 7 de janeiro de 1876 (Arquivo Imperial de Petrópolis). 
Comparadas à teoria da seleção das espécies, as idéias de Quatrefages, ou de Louis Agassiz foram as que ganharam mais adeptos no Brasil. Pouco depois que Quatrefages publicou seu livro sobre raças, Pedro II enviou-lhe uma remessa de amostras de fósseis, para análise, dentre as quais algumas daquelas descobertas por Lund. O mesmo ele fez com Virchow, na Alemanha, outro antropólogo anti-Darwin.

Os fósseis foram motivo de discussão entre o Imperador e Quatrefages, dentre os quais aqueles coletados por Lund. Este, durante os anos 1840, havia trabalhado nas grutas de Lagoa Santa, no Estado de Minas Gerais, onde coletou material fóssil. Em pouco tempo, tornou-se conhecido pois foi referência para Darwin, que citou o seu trabalho no livro A descendência do Homem ${ }^{32}$. Para Quatrefages, no entanto, os fósseis que lhe tinham sido enviados não permitia apresentá-los como símbolo da antiguidade do homem americano, pois tratava-se de fósseis bem mais recentes do que os do homem de Neandhertal. Suas conclusões opunham-se às de Lund, conseqüentemente às de Darwin. Ao mesmo tempo, permitia-se afirmar que, sobre a cultura social, a medida do crânio mostrava que era muitíssimo atrasada, ao contrário da idade dos fósseis. Pouco tempo depois ele sugeriu ao Imperador que organizasse uma nova expedição às cavernas onde havia estado Lund ${ }^{33}$.

No Museu Nacional do Rio de Janeiro os trabalhos de antropologia que foram se desenvolvendo e conseqüentemente desenvolvendo esta ciência no país, estavam de acordo com as teses de Quatrefages. Por seu lado, Quatrefages concordava com os trabalhos de antropologia - física - desenvolvidos no Museu Nacional, pelos médicos João Batista de Lacerda e Rodrigues Peixoto. Em 1878, por ocasião da Exposição Antropológica de Paris, a comunidade científica manifestou seu reconhecimento ao trabalho de Lacerda e o de Peixoto, outorgando-lhes medalhas ${ }^{34}$. Ambos haviam trabalhado os fósseis de Lund, cujos resultados foram publicados na revista do Museu Nacional, Archivos do Museu Nacional, em 1876. Sobre as conclusões de Lund, observava: O crânio fóssil da Lagoa Santa, uma das preciosidades da nossa coleção, assemelha-se muito por seus caracteres aos crânios dos Botocudos. Para Lacerda, os crânios que Lund coletara eram de Botocudos, isto é, os tipos mais atrasados na escala da cultura, que viviam no entanto «entre nós». Ele dizia que a um crânio como este correspondeu um grau de inferioridade intelectual muito próximo dos macacos antropofágicos ${ }^{35}$. Aproximou o homem do macaco, mas não admitiu a descendência. Para ele a tradição antropológica estava ligada a "Retzius, Morton, Prichard, Wagner»que tinham dado bases «modernas» aos estudos de "Broca, Pruner-Brey, Quatrefages, Wirchow, Topinard et outros que desenharam

${ }^{32}$ Darwin, Charles, The Descent of Man, and Selection in relation to sex. Princeton University Press, 1981. Reprint of the 1871 , ed. Published by J. Murray.

${ }^{33}$ Carta de Quatrefages a Pedro II, 27 de abril de 1874 (Arquivo Imperial de Petrópolis).

${ }^{34}$ Os diplomas de participação na Exposição Antropológica de Paris e medalhas que ambos receberam foram expostos na Exposição Antropológica Brasileira realizada em 1882 (Guia da Exposição ..., Museu Nacional, Rio de Janeiro, 1882, pp. 45 e 71).

${ }^{35}$ LACERDA, J. B. de - Contribuição para o estudo antropológico das raças indígenas do Brasil. Archivos do Museu Nacional do Rio de Janeiro, vol. I, Imprensa Nacional, 1876, p. 47-75. 
uma nova abordagem à ciência antropológica». Em um artigo de 1882, reafirmou que seu método, tal como o de Rodrigues Peixoto, seguia as Instruçóes de Broca ${ }^{36}$.

No trabalho sobre os fósseis de Lagoa Santa, Lacerda fez considerações comparativas deixando entrever algum princípio evolucionista, quando afirmou que o predomínio da dolicocefalia trazia argumentos para provar que a raça americana era dolicocéfala na sua maioria, mas que encontravam-se também tipos subdolicocéfalos e um mesaticéfalo, indicando que o Botocudo tendia a modificar-se pelo cruzamento com outra raça diferente, porém, pela sua pequena capacidade craneana os Botocudos devem ser colocados no mesmo nível dos Neo-Caledonios e dos Australianos, isto é, entre as raças mais notáveis pelo seu grau de inferioridade intelectual. As suas aptidóes são, com efeito, muito limitadas e difícil é fazê-los entrar no caminho da civilização. Concluía que o seu índice cefálico indicava uma dolicocefalia superior à dos patagônios e dos esquimós, as duas raças mais dolicocéfalas do mundo, o que o levava a admitir que no decurso de muitos séculos a raça dos Botocudos não tinha subido um só grau na escala da intelectualidade. - É um representante da raça pré-histórica, contemporânea do cavalo fóssil e outras espécies já extintas. Com tais afirmações o antropólogo inviabilizava a idéia de "civilizar o país», incluindo os índios.

Lacerda terminou aquele estudo refutando as conclusões de Lund e afirmando-se poligenista e criacionista "como Agassiz»: «Se é verdade que a formação do novo continente precedeu à formação do velho mundo, como quer Lund, fundado nas suas observaçôes geológicas sobre o plateau central do Brasil, se é exato, como diz Morton, que as mesmas crenças, os mesmos costumes, os mesmos ritos e até a mesma língua se encontram, com pequenas diferenças, em todos os povos esparsos no imenso território da América, não será talvez arrojada a proposição de Simonin quando diz que o Indio americano é um produto do solo americano!»37.

Os trabalhos sobre Lund, de Lacerda e os de Rodrigues Peixoto, mereceram comentários favoráveis na Academia de Ciências de Paris, em 1883, quando foram apresentados por Quatrefages. Este se dizia feliz ao poder fazer elogios tão merecidos aos dois naturalistas brasileiros. Segundo ele, Lacerda sublinhava as sensíveis diferenças que distinguiam esses crânios daqueles dos Botocudos ${ }^{38}$.

Uma outra análise dos dois brasileiros, que mereceu longos comentários de Quatrefages na Academia de Ciências de Paris, foi o estudo sobre o sambaquis, retornando à questão da origem dos povos, neste caso, dos americanos, que tanto ocupou a atenção dos cientistas nesta época. Da mesma forma, os sambaquis brasileiros foram objeto de trabalho de Virchow, na Alemanha, subsidiado que foi por um grupo de viajantes-naturalistas e pelos fósseis enviados pelo Imperador. Como bem mostrou Luiz Castro Faria, as análises de Virchow sobre os sambaquis brasileiros mudaram para

${ }^{36}$ Rodrigues PeiXoto, Novos Estudos Craniológicos sobre os Botocudos. Archivos do Museu Nacional, vol. VI, 1885, p. 208.

37 Idem, p. 74.

${ }^{38}$ Quatrefages, Note sur l'état des Sciences Naturelles et de l'Anthropologie au Brésil. Compte Rendu de l'Académie de Sciences de Paris, 1883, Vol. 96, p. 308-313 (Archives de l'Académie des Sciences de Paris). 
sempre a interpretação sobre eles, deixando claro que constituíam restos humanos ${ }^{39}$. No volume VI dos Archivos do Museu Nacional, João Batista de Lacerda publicou também um artigo sobre os sambaquis, intitulado O Homem do Sambaqui - Uma contribuição à Antropologia Brasileira, em que começou justificando-se que não estava à procura das origens, pois esta era uma questão que a ciência ainda não tinha solução, porém, sobre a evolução desses grupos podia afirmar que: Nas manifestações da atividade cerebral humana, sob o ponto de vista da arte ou da indústria, há, é verdade, uma infinita gradação que ascende desde o mais infimo representante da espécie até o mais portentoso produto dela. Salientando então a enorme diferença que existia entre os cérebros dos «brutos» austrálios e tasmânios e os de Miguel Ângelo ou Raphael. Para ele, o homem dos sambaquis não possuía, como os astecas e os peruanos, um cérebro afeiçoado às produçôes artísticas; sua inferioridade cerebral estava mesmo colocada a um nível tão baixo que não lhe permitia pensar em erguer monumentos cuja existência pressupunha um grau de civilização adiantada ${ }^{40}$.

Em outro trabalho, escrito com Rodrigues Peixoto, reafirmava a inferioridade social e/ou intelectual do homem do sambaqui: as raças aborígenes desta parte do novo mundo não deixavam sequer vestígios apagados de uma civilização incipiente; elas atravessaram os séculos, pela maior parte, na mais profunda barbárie e prolongaram até hoje essa longa e tenebrosa fase de sua vida primitiva. (...) No mesmo nivel de civilização, ou melhor dizer de profunda barbarie em que elas apareceram se conservam até hoje ${ }^{41}$. Aqueles restos arqueológicos, ainda hoje estudados para se conhecer a dieta dos indígenas, serviu para demarcar a hierarquia social.

Também este trabalho Quatrefages comentou na Academia de Ciências de Paris dizendo que a análise de Lacerda e a de Peixoto mostrava que os sambaquis eram os «koekkenmoedings» do Brasil concordando que os crânios analisados os aproximavam do dos Botocudos e testemunhavam a sua ancianidade ${ }^{42}$. Tais conclusões estavam totalmente de acordo com as dele, mesmo quando analisara diversos crânios americanos comparativamente aos fósseis descobertos por Lund.

Numa carta a Pedro II, referindo-se aos dois cientistas do Museu Nacional e também a Ladislau Netto, então Diretor do Museu, Quatrefages fez elogios aos trabalhos realizados na instituição brasileira dizendo que o Brasil entrava numa via de pesquisas sérias que não tocavam somente à história local, mas também a problemas os mais importantes da humanidade ${ }^{43}$. Os problemas a que se referia diziam respeito à colonização e à conquista dos últimos recantos da Terra, cuja natureza e os homens urgia que fossem conhecidos dos poderes imperialistas, então em expansão no mundo. As ciências naturais foram forte veículo do processo político internacional, nessa época.

${ }^{39}$ CASTro FARIA, Luiz, Virchow e os sambaquis brasileiros: um evolucionismo antidarwinista. (Org.) DOMingues, Romero SÁ e GLICK, 2003, op. cit., p. 125-143;

${ }^{40}$ Lacerda, J.B. - O Homem dos Sambaquis. Archivos do Museu Nacional do Rio de Janeiro, Vol. VI, 1885 , p. 175. Samaqui, mais comumente conhecido como casqueiro, era um lugar onde encontrava-se muitas conchas, e ossos de peixes, formando em geral montanhas.

${ }^{41}$ Lacerda \& Peixoto, 1876: 182.

${ }^{42}$ Quatrefages - Recherches sur les populations actuelles et préhistoriques du Brésil. Archives du Musée National.

${ }^{43}$ Carta de Quatregafes a Pedros II, Paris 11 de agosto de 1885 (Arquivo Imperial de Petrópolis). 


\section{Derivados de Darwin ou darwinismo no Brasil}

Desde o final do século XIX, até meados do século XX, o darwinismo no Brasil tornou-se, pode-se dizer, mais real. No Museu Nacional, Ladislau Netto, botânico, começou a discutir as questōes da evolução darwinista, mantendo, no entanto, uma posição ambígua. Como diretor do Museu, passou a fazer também antropologia que associou à arqueologia, porém, sem lançar mão da craniometria ${ }^{44}$. Seus trabalhos em botânica o haviam aproximado das conclusões de Haeckel, mas, seu evolucionismo sempre foi muito próximo do de Lamarck, bem formado que era na escola francesa, onde esteve por alguns anos no final da década de 1850 e início da de 60 .

$\mathrm{Na}$ Academia de Medicina surgiram teses utilizando os princípios darwinistas e na escola de Direito de Recife a teoria era ensinada principalmente a partir dos trabalhos de Haeckel e Spencer, que também não eram darwinistas, mas que, no entanto, não renegavam a teoria. Como bem observou um conhecido intelectual da época, Sylvio Romero, formado na escola de Recife, a questão da evolução fazia parte de diferentes disciplinas, além das ciências naturais, das ciências jurídicas e da história, e fornecia elementos para uma teoria geral da sociedade brasileira. Através dela era possível explicar sua marcha evolutiva submetida à ação do clima e do meio e as qualidades etnológicas das raças que haviam formado o seu povo. Segundo Sylvio Romero, Spencer fornecia para isso a teoria mais completa.

Para Sylvio Romero, a fórmula haeckeliana - «Cada povo que se desenvolve recapitula as fases anteriores da evolução da espécie humana» -, aplicada à sociedade, era exagerada e não muito acertada ${ }^{45}$. Discordava também de outra «lei» sociológica que dizia: "Sempre que uma sociedade se desloca de uma região para outra e o grupo civilizado se póe em contato e fusão com gentes em periodos inferiores de cultura, a história volta a séculos atrás e passa a recapitular sumariamente as fases passadas da história da humanidade». Ele se declarou identificado com o darwinismo poligenista e as teorias biológicas que aceitavam uma analogia entre animais e vegetais, como a de G. Tarde. Retomou as idéias de Spencer e a tese de Schäffe, que tinha concluído pela reprodução da filogênese pela ontogênese, afirmando que as colônias reproduzem com uma marcha mais acelerada, com mais intensidade, sobre uma extensão considerável, os estágios percorridos pelas civilizaçôes de alta cultura. Sylvio Romero aceitava a equalização da cultura social pela emergência das classes inferiores e concluía que as "raças", por mais estranhas que fossem, mostravam um paralelismo analógico nas várias fases do seu desenvolvimento.

Os estudos sobre as diferenças raciais que, no início do século XX, tomaram conta dos laboratórios de antropologia, de medicina e das ciências voltadas especificamente para o social, como o Direito, baseavam-se principalmente em Spencer e Haeckel, porém, ficaram conhecidos como darwinismo social. Esses estudos, no Brasil, tocavam diretamente a sociedade que era vista como um «laboratório racial» e, segundo Lilia Schwarcz, a miscigenação era tomada como sinal de enfraquecimento e decadência

${ }^{44}$ Tal fato foi observado também por CASTro FARIA, L. - As Exposições Antropológicas do Museu Nacional. Rio, Imprensa Nacional, 1949.

45 Idem, p. 201. Grifos do autor. 
da sociedade, pois, naquela época, raça e nação se equivaliam ${ }^{46}$. Quando se tratava de defender a hegemonia da prática do Direito ou uma certa hierarquia social, o argumento escorregava da cultura para a natureza, do indivíduo para o grupo, da cidadania para a raça ${ }^{47}$. Raça e nação se confundiam e o Brasil se via como uma sociedade enfraquecida, porque miscigenada, observou ainda Schwarcz.

Contudo, no Brasil, onde a teoria de Darwin foi inaugurada, deu-se também a sua reafirmação através da genética, no século XX. A genética foi uma importante via da concretização da teoria no Brasil, que tomou impulso maior com as viagens de Dobzhansky, ao país, na década de $1940^{48}$. Era ensinada, desde os anos 1920, nas escolas de Agricultura, de São Paulo, com base na teoria evolucionista de Lamarck, mas também, na darwinista de Fisher ${ }^{49}$. Dobzhansky chegou ao Brasil, com financiamento da Rockefeller, para estudar populações genéticas de zonas tropicais, pois, depois de analisar os estudos teóricos de Wright, Fisher, Haldane e Müller, concluiu que se restringiam a zonas temperadas ${ }^{50}$. Ele estudou, com sucesso populações de Drosophilas em diferentes lugares no país. Thomas Glick, no seu estudo pioneiro, mostrou que Dobzhansky deixou como saldo de seu trabalho no Brasil, não somente os resultados revolucionários para o darwinismo, como também, estruturou um sólido grupo de pesquisa em genética, na Universidade de São Paulo.

\section{Conclusão}

No Brasil, como em tantos países, a introdução da teoria da seleção das espécies por seleção natural ocorreu num clima de confronto, porém, não se pode falar em hostilidades entre os cientistas. As diferentes posições relativas à teoria de Darwin ficaram bem evidenciadas no Museu Nacional, por exemplo, onde conviveram as teses darwinistas de Müller com as contrárias, de Lacerda e Peixoto, e com a indecisa de Ladislau Netto. Seus trabalhos mereceram reconhecimento num dos fóruns científicos mais importantes da época, senão o mais importante, a Academia de Ciências de Paris, que era também um dos fóruns de maior oposição a Darwin.

Por outro lado, foram as idéias dos haeckelianos e spencerianos, como Sylvio Romero, Tobias Barreto e outros, que tiveram maior repercussão no Brasil e que também não podiam ser considerados darwinistas. Somente no século XX, com os trabalhos desenvolvidos nos Institutos de Agricultura, do Estado de São Paulo, e, depois, com os trabalhos realizados por Dobzhansky pode-se dizer que a zoologia, talvez a ciência menos estudada até agora pelos historiadores da ciência no Brasil, centralizou, com sucesso, as pesquisas baseadas na teoria de Darwin, até meados do século XX.

46 ShWarcZ, Lilia M., O espetáculo da miscigenação, (Org.) Domingues, Romero SÁ e Glick, 2003, p. $165-180$

${ }^{47}$ Idem, p. 171.

${ }^{48}$ GLICK, T. A Fundação Rockefeller e a emergência da genética no Brasil, (Org.) DOMINGUES, ROMERO SÁ e GLICK, 2003, p. 145-163.

${ }^{49}$ Idem, p. 146.

${ }^{50}$ Idem, p. 147. 
De um modo geral não se pode desvincular as questôes tratadas pelo teóricos do evolucionismo, no século XIX, do processo político e intelectual de afirmação da ideologia nacional, porém, em geral, ao vinculá-los, fala-se em subordinação da ciência ao político, porém, não teria sido o contrário? A política foi um ventríloquo das ciências naturais e a teoria da evolução, tal como interpretada, serviu ao imperialismo. No século XX os estudos do darwinismo, ao contrário, começaram a abrir o caminho da ecologia, do que encontramos um exemplo nos trabalhos de Dobzhansky. 
(Página deixada propositadamente em branco) 


\section{Calecçẫa \\ ป Ciências e Culturas Caimbra 2006}

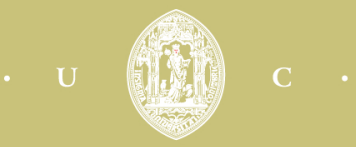

